\title{
Evaluation of the Bond Strength of Densely Sintered Ceramics Subjected to Extended Firing
}

\author{
Samuel Oliveira Costa' \\ Suellen Nogueira Linares \\ Lima (D) \\ Maria Victória Nassif $\left(\mathbb{D}^{2}\right.$ \\ Andres Felipe Millan \\ Cardenas $\mathbb{D}^{\prime}$ \\ Rudys Rodolfo de Jesus \\ Tavarez (D) \\ Darlon Martins \\ Lima ${ }^{3}{ }^{3}$ \\ Matheus Coelho Bandeca (iD) 2,3 \\ 'Post-Graduation Program in Dentistry, \\ CEUMA University, São Luis, Maranhão, \\ 65075-I20, Brazil; ${ }^{2}$ Post-Graduation \\ Program in Dentistry, University of Tuiuti \\ of Paraná, Curitiba, 82010-330, Brazil; \\ ${ }^{3}$ Post-Graduation Program in Dentistry, \\ Federal University of Maranhão, São Luis, \\ Maranhão, Brazil
}

Introduction: Critical failures in ceramic materials can be caused by the processing mode, which includes all steps taken in the manufacture of a ceramic part, from molding to firing. Purpose: To evaluate the effect of extended firing on bond strength in densely sintered ceramics of the zirconium reinforced lithium silicate, lithium disilicate, and feldspathic ceramic.

Materials and Methods: Three types of ceramics were evaluated: zirconium reinforced lithium silicate, lithium disilicate, feldspathic ceramic. A total of 6 ceramic blocks, two for each material were used in the study. Each block was cut into four square sections. A total of 24 ceramic surfaces were randomly distributed into 6 groups $(n=4$ surfaces per group) divided according to the variables: heat treatment: conventional firing or extended firing; test time: immediate (24 hours after cementation) or longevity (after 1000 cycles of thermocycling). The bond strength tests were performed in a semi-universal test machine for microshear bond strength. For data analysis, the Shapiro-Wilk test was performed to evaluate the normality between the groups measured, and regarding homoscedasticity (homogeneity of variances) by the Bartlett test. The comparisons between the groups were made using the nonparametric Kruskal-Wallis test.

Results: There was no statistically significant difference of the resistance values in relation to the thermal treatment methods (conventional firing and extended firing) in any ceramic group ( $\mathrm{p}<0.05$ ). Among the times (immediate and long), there was a statistically significant difference $(\mathrm{p}<0.05)$, with higher resistance values for immediate time.

Conclusion: Extended firing did not influence the micro-shear bond strength of zirconium reinforced lithium silicate, lithium disilicate, feldspathic ceramic.

Keywords: ceramics, CAD/CAM, dental cements, thermal cycle

\section{Introduction}

Dental ceramics are materials that have excellent mechanical, optical, and biological properties. ${ }^{1-3}$ These characteristics have enabled ceramics to perform better than other restorative materials because of their good compressive strength, excellent marginal integrity, color stability, and biomimicry. ${ }^{2,4,5}$ With the development of new technologies for processing these materials, such as CAD/CAM (ComputerAided Design/Computer-Aided Manufacturing) systems, the manufacturing process of ceramic restoration has become faster and more convenient, leading to the use of these materials in several applications. ${ }^{5-7}$

This growing evolution has allowed for significant changes in its physical, mechanical, and aesthetic properties, leading to the development of restorative systems with distinct clinical and laboratory characteristics, such as alumina, leucite, lithium disilicate, zirconia, and hybrid ceramics. ${ }^{3,8,9}$
Correspondence: Matheus Coelho Bandeca Post-Graduation Program in Dentistry, CEUMA University, Josue Montello, Renascença, São Luis, Maranhão, 65072-I20, Brazil

Tel +5598982232998

$\mathrm{Fax}+559832144127$

Email mbandeca@gmail.com 
Lithium disilicate, zirconium-reinforced lithium silicate, and feldspathic ceramics can be machined using $\mathrm{CAD} / \mathrm{CAM}$, in which densely sintered blocks are milled into the desired restoration shape. ${ }^{3,7,8}$ Recent studies have shown that the appearance of failures in ceramic restorations milled using $\mathrm{CAD} / \mathrm{CAM}$ systems is relatively low, ranging from 7 years or more. ${ }^{10}$

However, ceramic fracture is still one of the major modes of technical failure or complication in clinical studies, and requires further investigation. ${ }^{5,8}$

Among the main critical failures in ceramic materials are those caused by the processing mode, which includes all the steps performed in the manufacturing of the part, from molding to firing. ${ }^{1,6}$ These common failures involve damage to the internal and external surface of the restoration during $\mathrm{CAD} /$ CAM milling. ${ }^{6,11,12}$ In addition, the finishing procedures recommended by the manufacturer, such as conventional firing, are insufficient to reduce the damage caused to the ceramic surface during machining. ${ }^{1,6,11,12}$ Hence, imperfections caused during the milling process can trigger propagation points resulting in catastrophic damage. Furthermore, a few studies suggest a possible deleterious effect of conventional firing on machined vitroceramic materials. ${ }^{1,6,11}$

Aurélio et al ${ }^{1,6,11}$ developed an alternative method for conventional firing of densely sintered glass-ceramics, including extended firing, which led to tolerable residual stresses, clinically acceptable color changes, and microstructural stability of the ceramic surfaces after the heat treatment. The extended firing significantly increased the flexural strength of glass-ceramics after machining, compared to firing recommended by the manufacturer. ${ }^{1,6,11}$

The findings of improved mechanical performance of ceramics subjected to extended firing ${ }^{1,6,11}$ have allowed for the use of ceramic of reduced thickness, ${ }^{13,14}$ more conservative preparation methods and consequently, minimal wear of the tooth structure. ${ }^{15,16}$ However, the bonding of ceramic materials to dental substrates is a complex adhesive process and subject to different alterations of the ceramic substrate. ${ }^{13,14,17}$

There have been significant structural improvements in vitroceramics subjected to extended firing, and there is a need to link them to adhesive procedures ${ }^{18}$ to achieve clinical success of CAD/CAM ceramic restorations. A high-quality adhesion of the resin cement to the tooth structure and restorating surface is primordial for the success of bonding. ${ }^{19}$ Hence, tests assessing the bond strength of these ceramics to resinous materials after the proposed treatment are necessary. Beyond the evaluation of the initial adhesion, the maintenance of the bond after continued use is paramount for significant adoption. ${ }^{5}$ When adhesive interfaces are submitted to aging, they tend to degrade and drastically compromise the bonding between resin cement and glass ceramic., ${ }^{5,20}$

Therefore, the objective of this study is to evaluate the effect of extended firing on the bond strength of densely sintered ceramics of the zirconium-reinforced lithium silicate, lithium disilicate, and feldspathic ceramic. The null hypothesis that is tested is that the extended firing has no influence on the bond strength of densely sintered ceramics tested.

\section{Materials and Methods}

\section{Sample Preparation}

Three CAD/CAM (Computer-Aided Design/ComputerAided Manufacturing) (Figure 1) ceramics were selected for the study: 1) zirconium reinforced lithium silicate (Celtra Duo - Dentsplay - 45080); 2) lithium disilicate (IPS e.max CAD - Ivoclar Vivadent - 554980); and 3) feldspathic ceramic (Cerec Blocs - SIRONA - 51250).

A total of 6 ceramic blocks for CAD/CAM, two for each material, were used. Each ceramic block $(12 \times$ $12 \times 6 \mathrm{~mm})$ was cut into 4 cubic parts $(6 \times 6 \times 6 \mathrm{~mm})$ using a low rotation diamond disc under (Isomet Buehler; Lake Bluff, IL, USA) constant water lubrication. Subsequently, the surface roughness was standardized

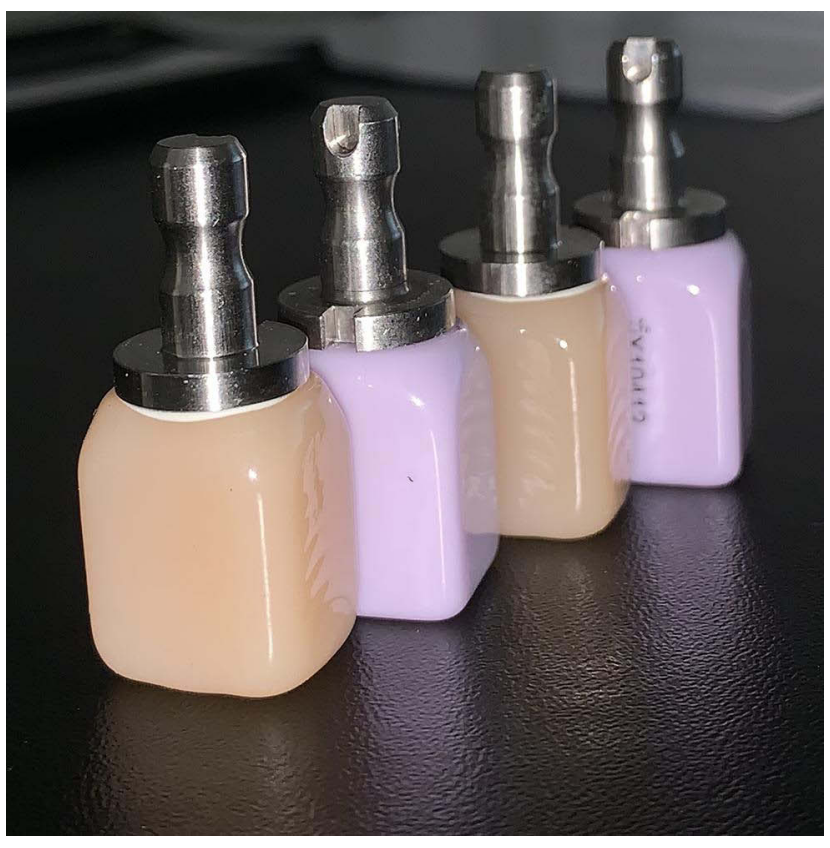

Figure I Ceramics CAD/CAM. 
using silicon carbide sandpaper 600 granulation (CarbiMet, Buehler Ltd., Lake Bluff, IL, EUA) under water lubrication, with friction for 60 seconds.

Each ceramic group underwent two different heat treatments (Pro-gramart P300, Ivoclar Vivadent): 1) according to the manufacturer's recommendations ie, conventional firing; 2) according to the protocol tested ie, extended firing (Table 1). ${ }^{1}$

\section{Experimental Design}

According to the ceramic used and the proposed heat treatment, the ceramic surfaces $(n=24)$ were randomly distributed (http://www.sealedenvelope.com) into 6 groups ( $\mathrm{n}=4$ ceramic surfaces per group): 1 . zirconia-reinforced lithium silicate (ZLS) - conventional glaze firing (CG); 2. lithium disilicate (DIS) - CG; 3. feldspathic ceramic (FEL) - CG; and 4. ZLS - extended glaze firing (EG); 5. DIS - EG; 6. FEL - EG (Table 1).

\section{Surface Treatment of Ceramics}

The sintered ceramic surfaces were mounted on a polyvinyl chloride (PVC) ring filled with acrylic resin (AutoClear, DentBras; Pirassununga, São Paulo, Brazil), leaving the sample surface at a height of $3 \mathrm{~mm}$ from the top of the cylinder (Figure 2). The surfaces were conditioned with 10\% hydrofluoric acid (Condac Porcelana 10\% FGM; Joinville, SC, Brazil) for 30 seconds and dry the surface with an air jet. The silane bonding agent (RelyX Ceramic Primer, 3M, São Paulo, Brazil) was actively applied with friction for 60 seconds with the aid of a disposable applicator (Cavibrush, FGM; Joinville, SC, Brazil). For the adhesive system (Adper Single Bond 2, 3M, São Paulo, Brazil), a layer was applied with vigorous friction for 20 seconds. The evaporation of the solvent was conducted gently with an air jet for at least 5 seconds, without carrying out photopolymerization for all ceramic surfaces.

After applying the adhesive system, 12 transparent polyethylene tubes (Tygon Medical Tubing Formulations 54-HL, Saint Gobain Performance Plastics; Akron, OH, USA) of $0.8 \mathrm{~mm}$ internal diameter and $0.5 \mathrm{~mm}$ height were positioned on each ceramic surface. The resin cement (RelyX Veneer, 3M, São Paulo, Brazil) was carefully inserted into each tube, followed by light curing for 30 seconds, using a $1200 \mathrm{~mW} / \mathrm{cm}^{2}$ light cure unit (Radii-cal, SDI; Bayswater, Victoria, Australia).

The specimens were stored in distilled water for $24 \mathrm{~h}$ at $37^{\circ} \mathrm{C}$ and the tygon tubes were carefully removed with scalpel blade until the cement cylinders were exposed. The cement cylinder was discarded if there was evidence of porosity or bubbles at the interface.

\section{Micro Shear Bond Strength ( $\mu$ SBS) Tests}

Half of the specimens in each group were tested after $24 \mathrm{~h}$ of storage. The other half were thermocycled $(n=24)$ for 1000 cycles at 5 and $55^{\circ} \mathrm{C}$ for 30 seconds each, with an intermediate bath at $37^{\circ} \mathrm{C}$ for 30 seconds in a thermal cycling machine (Model 521-4D - Nova Ética Ind., Com e Serv Ltda, Vargem Grande Paulista - SP, Brazil). ${ }^{5}$ The samples were mounted in a micro-shear test machine

Table I Description of the Experimental Groups According to the Treatments Applied to the Ceramic Materials

\begin{tabular}{|c|c|c|c|c|c|c|}
\hline \multicolumn{7}{|c|}{ Groups $(n=6)$} \\
\hline & ZLS-CG & DIS-CG & FEL-CG & ZLS-EG & DIS-EG & FEL-EG \\
\hline Ceramic & ZLS & DIS & FEL & ZLS & DIS & FEL \\
\hline Glaze Firing & \multicolumn{3}{|c|}{ Conventional Glaze Firing (CG) } & \multicolumn{3}{|c|}{ Extended Glaze Firing (EG) } \\
\hline Initial temperature $\left({ }^{\circ} \mathrm{C}\right)$ & 400 & 403 & 500 & 400 & 403 & 500 \\
\hline Temperature increase rate $\left({ }^{\circ} \mathrm{C} / \mathrm{min}\right)$ & 80 & 60 & 80 & 80 & 60 & 80 \\
\hline Final temperature $\left({ }^{\circ} \mathrm{C}\right)$ & 800 & 770 & 950 & 800 & 770 & 950 \\
\hline Dwell time at the final temperature $(\mathrm{min})$ & ।:00 & $1: 30$ & ।:00 & 15:00 & $15: 00$ & $15: 00$ \\
\hline Cooling rate & \multicolumn{3}{|c|}{$\begin{array}{l}\text { Fast. Immediate furnace opening after the } \\
\qquad \text { dwell time }\end{array}$} & \multicolumn{3}{|c|}{$\begin{array}{l}\text { Slow. The furnace remained closed until the materia } \\
\text { reached } 200^{\circ} \mathrm{C}\end{array}$} \\
\hline
\end{tabular}

Abbreviations: ZLS-CG, zirconia-reinforced lithium silicate - conventional glaze firing; DIS-CG, lithium disilicate - conventional glaze firing; FEL-CG, feldspathic ceramic conventional glaze firing; ZLS-EG, zirconia-reinforced lithium silicate - extended glaze firing; DIS-EG, lithium disilicate - extended glaze firing; FEL-EG, feldspathic ceramic extended glaze firing; ${ }^{\circ} \mathrm{C}$, graus Celsius; Min, minutes. 


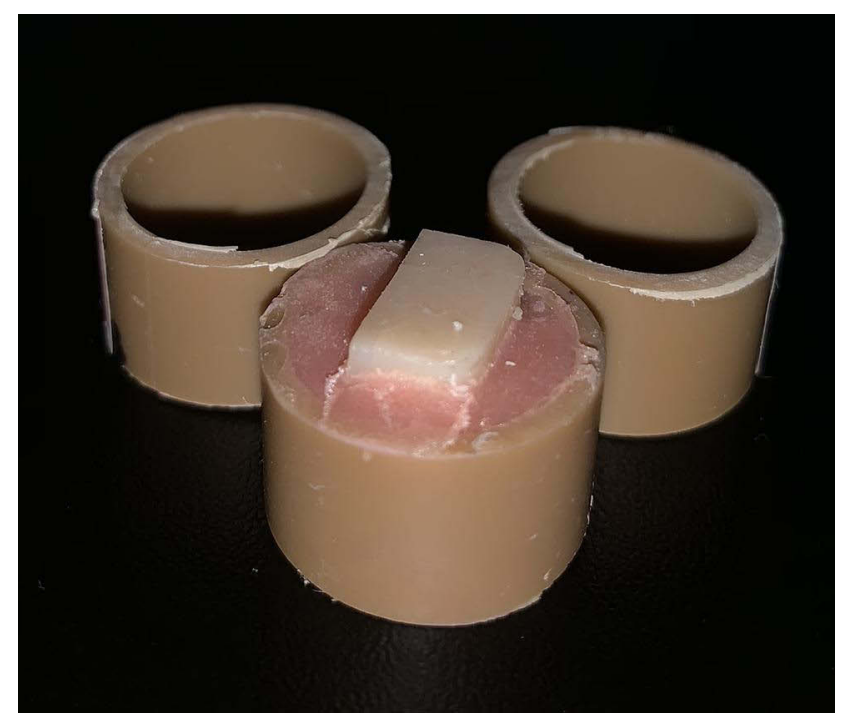

Figure 2 Ceramic surfaces mounted on a polyvinyl chloride (PVC).

(Microtensile Semi-universal, ODEME, Joaçaba, SC, Brazil), where the specimens were tested using an orthodontic archwire $(0.2 \mathrm{~mm} \text { diameter })^{21,22}$ adapted around the base of each resin cement cylinder. After being positioned at the base of the cylinder, the orthodontic wire was aligned with the center of the load cell to ensure the correct orientation of the shear force. ${ }^{17}$ The specimens were pulled until the adhesive interface ruptured, and the values of bond strength (MPa) to micro shear were noted.

After the tests, the ceramic surfaces were evaluated under an optical microscope (SZH-131, Olympus; Tokyo, Japan) with 100X magnification to define the failure mode. The failure mode was classified as, cohesive in resin cement ([CCR] fails exclusively in resin cement Figure 3), cohesive in ceramic ([CC] fails exclusively in ceramic - Figure 4), and adhesive/mixed ([A/M] fails in cement-ceramic interface/partial cohesive failure in neighboring substrates - Figure 5).

\section{Statistical Analysis}

All groups measured were evaluated for data normality by the Shapiro-Wilk test, and for homoscedasticity (homogeneity of variances) by the Bartlett test. As a few groups did not have a normal distribution, and there was no homoscedasticity between them, comparisons between groups were made using the nonparametric Kruskal-Wallis test.

In all tests, a $5 \%$ significance level $(\mathrm{p}<0.05)$ was adopted. The statistical procedures were carried out using Statistica programme version 10 (StatSoft Inc., Tulsa, USA).

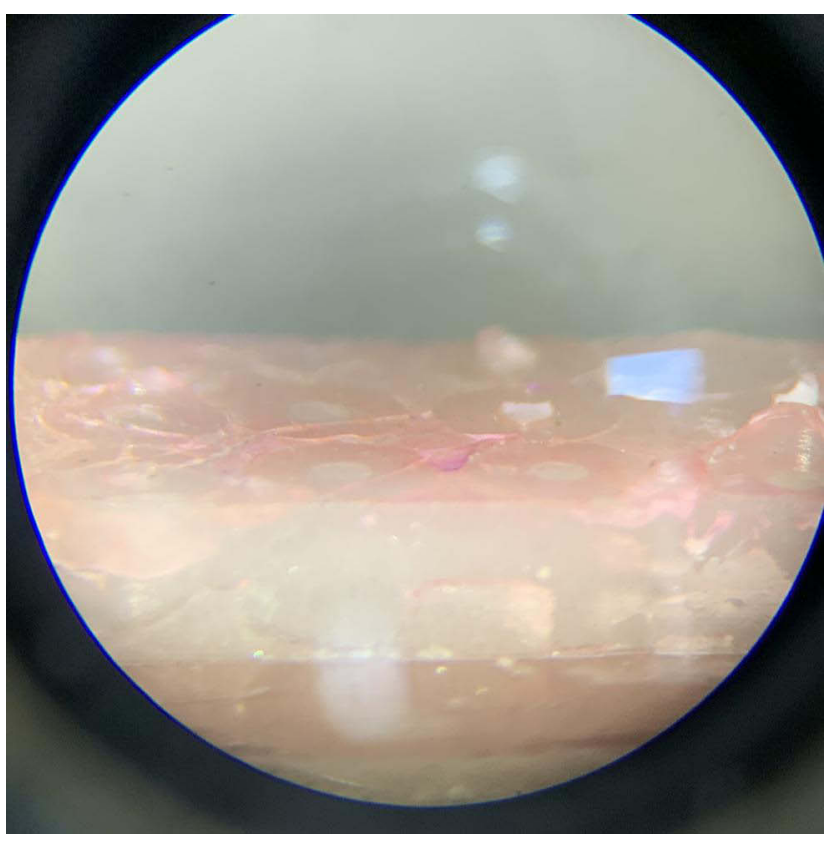

Figure 3 Failure cohesive in resin cement.

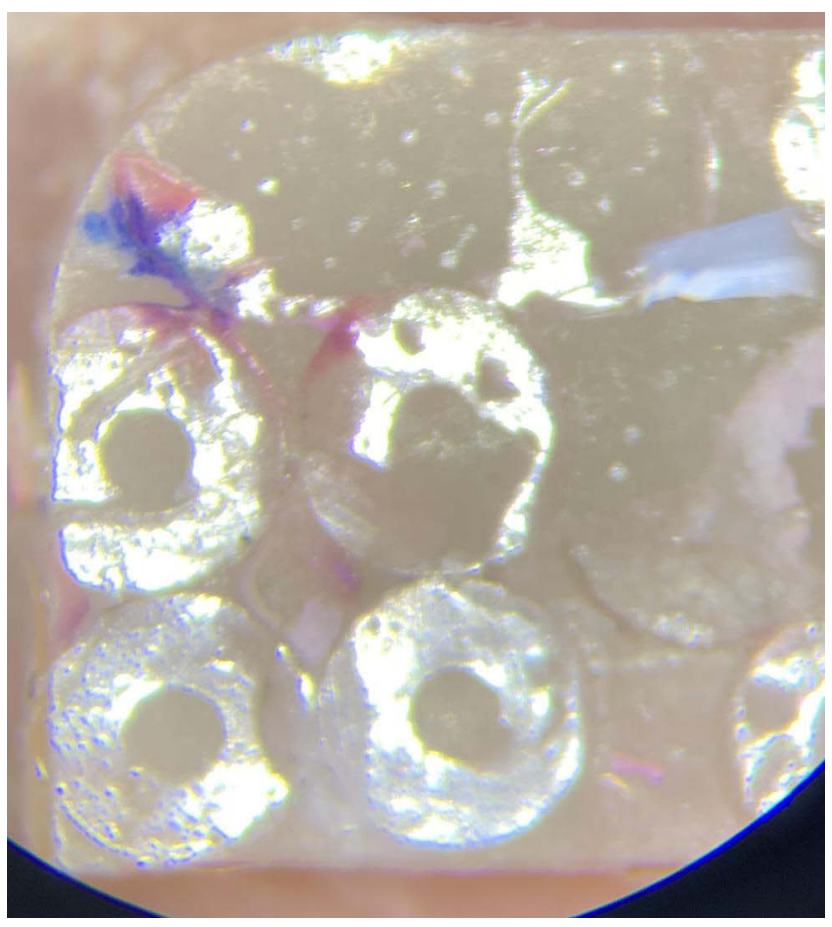

Figure 4 Failure cohesive in ceramic.

\section{Results}

No specimens were discarded due to the presence of porosity or other defects nor were pre-test failures observed. A total $88.4 \%$ of the specimens showed adhesion/mixed failure (Table 2). 


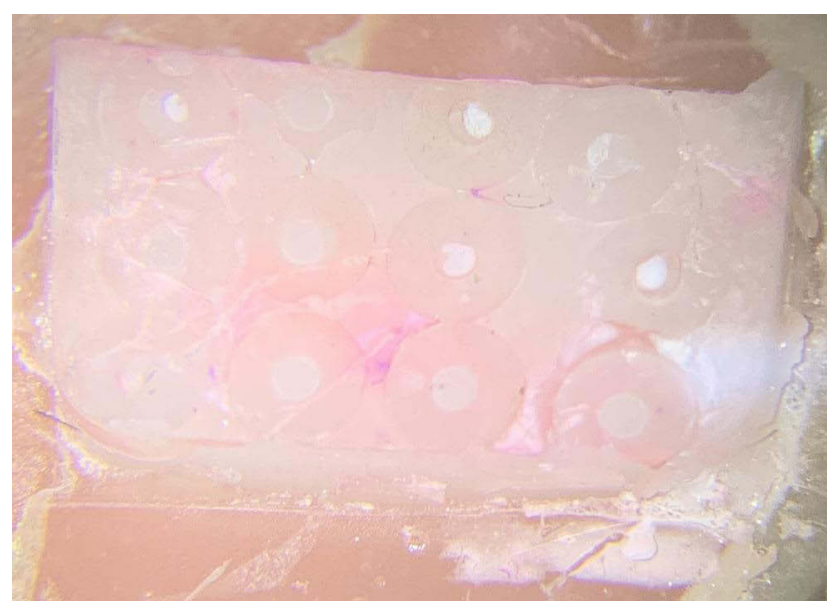

Figure 5 Failure adhesive/mixed.

There was no statistically significant difference $(\mathrm{p}<0.05)$ among the resistance values in relation to the methods of heat treatment (conventional firing and extended firing) in any ceramic group. Among the times (immediate and long), there was a statistically significant difference $(\mathrm{p}<0.05)$, with higher resistance values for immediate times (Table 3).

\section{Discussion}

The present study aimed to analyze the effect of the extended firing protocol on the bond strength of densely sintered ceramics of the zirconium reinforced lithium silicate, lithium disilicate, and feldspathic ceramic. The null hypothesis tested is hereby accepted, as it has been verified that the extended firing has no influence on the bond strength of zirconiareinforced lithium silicate, lithium disilicate, and feldspathic ceramics. Likewise, the thermocycling also did not influence the bond strength in lithium silicate reinforced with zirconia, lithium disilicate and feldspar ceramic, because there were no significant differences between the micro-shear values in the ceramics subjected to extended firing.
The clinical success of ceramic restorations depends on several factors, like the cementation procedure, composition of the ceramic material and the different alterations of the ceramic substrate ${ }^{18}$. Despite that, the findings of the present study showed that the extended firing of the different ceramics tested did not cause deleterious effects for the micro-shear bond strength of these materials. According to Aurélio et $\mathrm{al}^{1,6,11}$ the feasibility of using alternative thermal regimes such as extended firing was advantageous since significantly increased the bending resistance, reduced surface roughness and did not alter the microstructure of glass-ceramic samples.

It has been demonstrated that hydrofluoric acid selectively dissolves the glass matrix of ceramics producing a porous and irregular surface that facilitates the micromechanical retention of these restorations promoted by the application of an adhesive and resin cement system. ${ }^{14,23}$

In the present study, the internal surfaces of ceramics exposed to EG did not show significant differences in adhesive bond strength when compared to CG groups. In the studies by Aurélio et al, ${ }^{1,6}$ it was observed that the extended firing reduced the surface roughness of glass ceramics and did not change the microstructure of the samples after machining. The protocol of heat treatment with temperature increase did not cause changes in the degree of crystallization of the material. ${ }^{6}$ It is inferred that the decrease in surface roughness of the ceramics, caused by the heat treatment, did not influence the dissolution of the glass matrix by hydrofluoric acid, as the microshear values for the ceramic groups did not show significant difference. Thus, it is inferred that extended firing is incapable of producing significant changes in the microstructure of vitroceramics, corroborating the idea that it can be advantageous for the adhesive process. Therefore, intrinsically stable ceramics and with better mechanical

Table 2 Percentage (\%) of Specimens According to Failure Mode

\begin{tabular}{|l|l|l|l|l|l|l|l|l|l|l|l|l|l|}
\hline \multicolumn{9}{|c|}{ Failure Mode } \\
\hline Ceramic & \multicolumn{10}{l|}{ CG Immediate } & \multicolumn{2}{l|}{ EG Immediate } & \multicolumn{2}{l|}{ CG Longevity } \\
\hline & CCR & CC & A/M & CCR & CC & A/M & CCR & CC & A/M & CCR & CC & A/M \\
\hline ZLS & 50 & 0 & 50 & 4 & 0 & 96 & 18 & 0 & 82 & 0 & 0 & 100 \\
\hline DIS & 7 & 0 & 93 & 14 & 0 & 86 & 5 & 0 & 95 & 3 & 0 & 97 \\
\hline FEL & 1 & 10 & 89 & 0 & 9 & 91 & 2 & 7 & 91 & 0 & 9 & 91 \\
\hline
\end{tabular}

Abbreviations: CG, Conventional glaze firing; EG, Extended glaze firing; ZLS, Zirconia-reinforced lithium silicate; DIS, Lithium disilicate; FEL, Feldspathic ceramic; CCR, Fails cohesive in resin cement; CC, Fails cohesive in ceramic; A/M, Fails adhesive/mix. 
Table 3 Mean and Standard Deviation of Bond Strength ( $\mu$ SBS) in MPa Intre-Group Comparasions

\begin{tabular}{|l|c|c|c|c|c|c|}
\hline Ceramic & CG Immediate & EG Immediate & Valor $\mathbf{p}$ & CG Longevity & EGLongevity & Valor $\mathbf{p}$ \\
\hline $\begin{array}{l}\text { ZLS } \\
\text { (median) }\end{array}$ & $\begin{array}{c}16.40 \pm 6.08 \\
14.54\end{array}$ & $\begin{array}{c}14.48 \pm 4.49 \\
14.40\end{array}$ & 1.000 & $\begin{array}{c}5.07 \pm 1.41 \\
5.38\end{array}$ & $\begin{array}{c}6.57 \pm 1.63 \\
6.48\end{array}$ & 1.000 \\
\hline $\begin{array}{l}\text { DIS } \\
\text { (median) }\end{array}$ & $\begin{array}{c}16.48 \pm 5.82 \\
15.99\end{array}$ & $\begin{array}{c}11.94 \pm 5.55 \\
12.95\end{array}$ & 0.053 & $7.46 \pm 1.33$ & $7.26 \pm 0.93$ & 1.000 \\
\hline $\begin{array}{l}\text { FEL } \\
\text { (median) }\end{array}$ & $\begin{array}{c}15.70 \pm 4.12 \\
19.11\end{array}$ & $\begin{array}{c}16.10 \pm 4.09 \\
19.11\end{array}$ & 1.000 & $\begin{array}{c}7.64 \pm 3.11 \\
11.30\end{array}$ & $\begin{array}{c}5.97 \pm 1.88 \\
5.83\end{array}$ \\
\hline
\end{tabular}

Note: For each group, different letters indicate a statistically significant difference $(p<0.05)$.

Abbreviations: CG, Conventional glaze firing; EG, Extended glaze firing; ZLS, Zirconia-reinforced lithium silicate; DIS, lithium disilicate; FEL, Feldspathic ceramic.

properties are favorable substrates for the establishment of the adhesive interface, especially for those with higher glassy content.

Another relevant factor related to the interaction of the adhesive interface is the type of silane agent used. ${ }^{20}$ In this study, it was proposed to use a pre-hydrolyzed product composed of 1) Ethyl alcohol; 2) Water; and 3) Trimethoxysilylpropyl methacrylate (MDP). A few studies have observed that ceramic surfaces treated with phosphate monomer solution (MDP) containing silane show a lower reduction in bond strength when compared to surface treatment with silane solution without MDP probably due to its chemical affinity with the structure. ${ }^{20,23,24}$ The correct protocol for the treatment of the ceramic substrate combined with ceramics treated with extended firing is potentially favorable for adhesion, since the bond strength values were statistically similar.

This proven benefit of the proposed heat treatment on the mechanical properties of glass-ceramics used for the fabrication of CAD/CAM restorations ${ }^{1,6,8,11}$ has not been able to produce changes in their microstructure to prevent or influence the adhesion resinous/ceramic cement. It is therefore suggested that the structural maintenance of the ceramic material due to the extended heat treatment allowed the establishment of the adhesive interface between ceramic and resin cement. Nevertheless, it is also suggested that the adhesive cement/ceramic interface also takes advantage of the protocol, although no significant differences have been found.

It is worth noting that in this study, half of the ceramic surfaces of each group underwent thermocycling for 1,000 cycles. A significant reduction in the mean values of bond strength was found in all groups after thermocycling, which is in accordance with other studies. ${ }^{4,20,24}$ These results suggest a significant clinical impact over the long term, as vitroceramic restorations can fail clinically. ${ }^{1,3,5,25}$
Adhesive or mixed failure mode in thermocycling vitroceramics is more prevalent than tests performed 24 hours after cementation. ${ }^{14,17,20}$ Following the micro-shear bond testing procedure, all the samples were observed under a stereomicroscope at $\times 100$ magnification to identify the nature of bond failure, namely, cohesive, adhesive, or a combination of both. Although failure data has not been statistically assessed, the results obtained showed that percentage of adhesives/mixed failure increased after thermocycling in all tested ceramic groups. In the ZLS groups, this observation was clear, since the reduction in the prevalence of cohesive failures in cement was very relevant.

In this context, the present study corroborates the literature, showing a higher number of adhesive/mixed failures after thermal aging. This change in failure modes and the decrease in bond strength suggest that this chemical bond is not stable over time and is probably related to the hydrolytic degradation of the adhesive interface that occurs during the storage period. ${ }^{20,24,26}$ Otherwise, the difference in the coefficient of thermal expansion between the restorative materials might induce degradation of adhesive interface. ${ }^{5,12}$

This in vitro study has some limitations. Although thermocycling was carried out, the aging with thermocycling does not adequately simulate clinical conditions in every detail. Subjecting the specimens to dynamic loading in artificial saliva before testing may closely resemble intraoral conditions with respect to hydrolytic degradation of the bond due to $\mathrm{pH}$ changes of saliva and the effect of temperature change in the mouth. Furthermore, the final evaluation of material performance should be determined using long-term clinical studies with densely sintered ceramics subjected to extended firing.

\section{Conclusion}

Based on the results of the present study and within the conditions and limitations of this in vitro study, the 
extended firing did not influence the micro-shear bond strength of zirconia, lithium disilicate, and feldspathic ceramics. Thermocycling affected the mean micro-shear bond strength of both the thermal regimes for the all the ceramics groups.

\section{Disclosure}

The authors report no conflicts of interest in this work.

\section{References}

1. Aurélio IL, Dorneles LS, May LG. Extended glaze firing on ceramics for hard machining: crack healing, residual stresses, optical and microstructural aspects. Dent Mater. 2016;33(2):226-232.

2. Belli R, Petschelt A, Hofner B, Hajto J, Scherrer SS, Lohbauer U. Fracture rates and lifetime estimations of CAD/CAM all-ceramic restorations. J Dent Res. 2016;95(1):67-73.

3. Borges GA, Sophr AM, de Goes MF, Sobrinho LC, Chan DC. Effect of etching and airborne particle abrasion on the microstructure of different dental ceramics. J Prosthet Dent. 2003;89(5):479-488.

4. Curran P, Cattani-Lorente M, Anselm Wiskott HW, Durual S, Scherrer SS. Grinding damage assessment for CAD-CAM restorative materials. Dent Mater. 2017;33(3):294-308.

5. Rossomando KJ, Wendt SL Jr. Thermocycling and dwell times in microleakage evaluation for bonded restorations. Dent Mater. 1995;11(1):47-51.

6. Aurélio IL, Fraga S, Dorneles LS, Bottino MA, May LG. Extended glaze firing improves flexural strength of a glass ceramic. Dent Mater. 2015;31(12):316-324.

7. Otto T, Schneider D. Long-term clinical results of chairside Cerec CAD/CAM inlays and onlays: a case series. Int $J$ Prosthodont. 2008;21(1):53-59.

8. Fraga S, Valandro LF, Bottino MA, May LG. Hard machining, glaze firing and hydrofluoric acid etching: do these procedures affect the flexural strength of a leucite glass-ceramic? Dent Mater. 2015;31 (7):131-140.

9. Ozturk N, Usumez A, Usumez S, Ozturk B. Degree of conversion and surface hardness of resin cement cured with different curing units. Quintessence Int. 2005;36(10):771-777.

10. Fages M, Raynal J, Tramini P, Cuisinier FJ, Durand JC. Chairside computer-aided design/computer-aided manufacture all-ceramic crown and endocrown restorations: a 7-year survival rate study. Int J Prosthodont. 2017;30(6):556-560.

11. Aurélio IL, Prochnow C, Guilard LF, Ramos GF, Bottino MA, May LG. The effect of extended glaze firing on the flexural fatigue strength of hard-machined ceramics. J Prosthet Dent. 2018;120 (5):755-761.
12. Benetti P, Kelly JR, Sanchez M, Della AB. Influence of thermal gradients on stress state of veneered restorations. Dent Mater. 2014;30(5):554-563.

13. Kim JH, Chae SY, Lee Y, Han GJ, Cho BH. Effects of multipurpose, universal adhesives on resin bonding to zirconia ceramic. Oper Dent. 2015;40(1):55-62.

14. Quemard L, Rebillat F, Guette A, Tawil H, Louchet-Pouillerie C. Degradation mechanisms of a SiC fiber reinforced self-sealing matrix composite in simulated combustor environments. $J$ Eur Ceram Soc. 2007;27(1):377-388.

15. May LG, Robert Kelly J, Bottino MA, Hill T. Influence of the resin cement thickness on the fatigue failure loads of CAD/CAM feldspathic crowns. Dent Mater. 2015;31(8):895-900.

16. Shimada Y, Yamaguchi S, Tagami J. Microshear bond strength of dual cured resin cement to glass ceramics. Dent Mater. 2002;18 (5):380-388.

17. Pereira SG, Fulgêncio R, Nunes TG, Toledano M, Osorio R, Carvalho RM. Effect of curing protocol on the polymerization of dual cured resin cements. Dent Mater. 2010;26(7):710-718.

18. Siqueira F, Cardenas AM, Gutierrez MF, et al. Laboratory performance of universal adhesive systems for luting CAD/CAM restorative materials. J Adhes Dent. 2016;18(4):331-340.

19. Denry I, Holloway JA. Ceramics for dental applications: a review. Materials. 2010;3(1):351-358.

20. Cardenas AM, Siqueira F, Hass V, et al. Effect of MDP-containing silane and adhesive used alone or in combination on the long-term bond strength and chemical interaction with lithium disilicate ceramics. $J$ Adhes Dent. 2017;19(3):203-212.

21. Andrade MA, Moura KS, Reis A, Loguercio AD, Garcia EJ, Grande RHM. Evaluating resin-enamel bonds by microshear and microtensile bond strength tests: effects of composite resin. J. Appl. Oral Sci. 2010;18(6):591-598.

22. Lise DP, Perdigão J, Van Ende A, Zidan O, Lopes GC. Microshear bond strength of resin cements to lithium disilicate substrates as a function of surface preparation. Oper Dent. 2015;40(5):524-532.

23. Pereira GKR, Silvestri T, Amaral M, Rippe MP, Kleverlaan CJ, Valandro LF. Fatigue limit of polycrystalline zirconium oxide ceramics: effect of grinding and low temperature aging. $J$ Mech Behav Biomed Mater. 2016;61:45-54.

24. Matinlinna JP, Lassila LV. Experimental novel silane system in adhesion promotion between dental resin and pretreated titanium. Part II: effect of long-term water storage. Silicon. 2010;2:79-85.

25. Denry I. How and when does fabrication damage adversely affect the clinical performance of ceramic restorations? Dent Mater. 2013;29 (1):85-96.

26. Kalavacharla VK, Lawson NC, Ramp LC, Burgess JO. Influence of etching protocol and silane treatment with a universal adhesive on lithium disilicate bond strength. Oper Dent. 2015;40(4):372-378.

\section{Publish your work in this journal}

Clinical, Cosmetic and Investigational Dentistry is an international, peer-reviewed, open access, online journal focusing on the latest clinical and experimental research in dentistry with specific emphasis on cosmetic interventions. Innovative developments in dental materials, techniques and devices that improve outcomes and patient satisfaction and preference will be highlighted. The manuscript management system is completely online and includes a very quick and fair peer-review system, which is all easy to use. Visit http://www.dovepress.com/testimonials.php to read real quotes from published authors. 